\title{
EVALUACIÓN JURÍDICO-ECONÓMICA SOBRE EL DELITO EMPRESARIAL INTERNACIONAL*
}

\author{
Jahir Alexánder Gutiérrez Ossa**
}

Recibido: marzo 02 de 2010

Aceptado: enero 20 de 2011

\section{RESUMEN}

Este artículo evalúa el contexto jurídico-económico de los delitos cometidos en las empresas internacionales, y la aparente incapacidad del derecho penal internacional para juzgar y reglar el comportamiento de éstas en los sistemas jurídicos. El elevado número de llamados a juicio hechos a las empresas para responder por estos actos muestra que aún no ha sido considerada la estructura legal internacional para atender dichas circunstancias. A partir de una revisión de la fundamentación teórica y de algunos casos, se identifican las debilidades del derecho internacional, al no estar articulado con las concepciones económicas para controlar las acciones de las empresas en los mercados internacionales. Se concluye que la entrada en vigencia del derecho penal económico, rama del análisis económico del derecho, puede servir de mecanismo evaluador de los delitos económicos empresariales, donde la valoración contractual del delito empresarial puede contribuir a superar la etapa del juicio por el resarcimiento.

\section{PALABRAS CLAVE}

Regulación y legislación en negocios; legislación penal; legislación internacional; análisis económico del derecho.

\section{CLASIFICACION JEL}

K20, K33, K42

\section{CONTENIDO}

Introducción, 1. Perspectiva de los sistemas de justicia internacional frente a los delitos empresariales, 2. El delito empresarial frente al derecho penal económico, 3. Delitos empresariales y acción de la justicia internacional; 4. Conclusiones, Bibliografía.

* Este artículo es producto del proyecto de investigación "La regulación económica colombiana frente a las exigencias globalizantes en materia de negocios comerciales internacionales: entre el proceso justo o el proceso eficiente", financiado por la Universidad de Medellín, iniciado en el segundo semestre de 2009 y ejecutado por el grupo de investigación en negocios internacionales (GINI), registrado en Colciencias categoría D, y el grupo de investigación en derecho procesal (GIDP), registrado en Colciencias categoría Al.

** Economista de la Universidad de Medellín, Colombia. Magíster en Desarrollo Regional y Local, Universidad Pontificia Bolivariana, Medellín, Colombia. Estudiante del Doctorado (PHD) en Administración Pública, Atlantic International University (AIU), Hawái, Estados Unidos. Estudiante de la especialización en Sistemas de Informacion Geográfica (SIG), Universidad San Buenaventura, Medellín, Colombia. Docente e investigador, Facultad de Administracion, Universidad CES en Medellín y Universidad del Rosario en Bogotá, Colombia. Tel: 4440555, Extensión 1411, Dirección: Calle 10A No 22-04, Bloque 4, oficina 04. Correo electrónico: lgutierrez@ces. edu.co. 


\section{LEGAL-ECONOMIC EVALUATION ON THE INTERNATIONAL ENTERPRISE FELONY}

\section{ABSTRACT}

This article evaluates the legal-economic contexts of committed felonies by international companies, and the apparent lack of capacity shown by the international penal law to control and regulate the behavior of this companies by the existent legal systems. The many attempts to prosecute this acts proves that the proper international legal structure for controlling this type of circumstances has not been properly contemplated yet. Parting from the revision of the theory fundaments and some cases, the weaknesses of international law due to the lack of articulation with economic conceptions for controlling these companies in the international markets is proven. It is concluded then that the economic penal law which is the economic analysis branch of law is applied, it can work as evaluation mechanism for enterprise economic felonies and contribute to overcome this compensation trial.

\section{KEY WORDS}

Business regulation and legislation; penal legislation; International legislation; economic analysis of law.

\section{JEL CLASSIFICATION}

K20, K33, K42

\section{CONTENTS}

Introduction, 1. International justice system perspectives concerning Enterprise felonies, 2. Enterprise felony concerning economic penal law, , 3. Enterprise felonies and the action of the international justice; 4. Conclusions, Bibliography.

\section{AVALIAÇÃO JURÍDICO-ECONÔMICA SOBRE O DELITO EMPRESARIAL INTERNACIONAL RESUMO}

Este Artigo avalia o contexto jurídico-econômico dos delitos cometidos nas empresas internacionais, e a aparente incapacidade do direito penal internacional para regular o comportamento destas nos sistemas jurídicos. O elevado número de chamados a juízo feitos às empresas para responder por estes atos, mostram que ainda não há sido considerada a estrutura legal internacional para atender estas circunstancia. A partir de uma revisão da fundamentação teórica e de alguns casos identificam-se as debilidades do direito internacional não estando articulado com as concepções econômicas para controlar as ações das empresas nos mercados internacionais. Conclui-se que a entrada em vigência do direito penal econômico, rama do analise econômico do direito, pode servir de mecanismo avaliador dos delitos econômicos empresariais, onde a valoração contratual do delito empresarial pode contribuir a superar a etapa do juízo por ressarcimento.

\section{PALAVRAS-CHAVES}

Regulação e legislação em negócios; legislação penal; legislação internacional; analise econômico do direito.

\section{CLASSIFICAÇÃO JEL} K20, K33, K42

\section{CONTEÚDO}

Introdução, 1. Perspectiva dos sistemas de justiça internacional frene aos delitos empresariais, 2. O delito empresarial frente ao direito penal econômico, 3. Delitos empresariais e ação da justiça internacional; 4. Conclusões, Bibliografia. 


\section{INTRODUCCIÓN}

Los crecientes llamados a juicio a empresas y empresarios hechos por doquier en las principales economías del mundo, para responder ante prácticas catalogadas fuera del marco de la ley y del derecho, y que provocaron el desbarajuste de los mercados en los últimos años, motivan el análisis del papel que ha cumplido el derecho internacional para corregir estas acciones. La forma errática como fueron abordados cada uno de los casos, determinó la capacidad de respuesta y agilidad de los sistemas jurídicos para responder efectivamente a estas situaciones.

Los delitos determinados en cada uno de los casos se caracterizaron por el manejo de informacion privilegiada para favorecer a algunos socios, sobrevaloración de activos para atraer más inversión de las bolsas, adquisición de compañías para mejorar momentáneamente los indicadores de las compañías como en los casos de Enron y WorldCom, entre otras empresas, pero sin una fuente clara de recursos para hacer efectivo el pago por las mismas o el desembolso de grandes sumas de dinero dirigidas al pago de dividendos, utilizando recursos de reservas o empréstitos obtenidos para otros fines.

Las investigaciones preliminares arrojaron la existencia de una cierta correlación entre cada uno de los casos, aspecto que fue corroborado al determinarse vínculos entre ellas. Este patrón, sumado a la forma sistemática como se llevaron a cabo los delitos mostró que estos habían sido calculados previamente; de ahí el asombro que en principio declararon las autoridades jurídicas internacionales por la manera orquestada como se fueron presentando cada uno; el asombro fue mayor, cuando la estructura jurídica internacional se declaró incapaz de responder efectivamente ante dicho suceso generalizado. El tiempo que tomó la justicia internacional para interpretar, analizar y contextualizar la problemática causada por los delitos empresariales mostró la realidad jurídica en dichos campos, la razón éstaque impulsa a considerar el tema en la actualidad.

Las circunstancias provocadas por los delitos empresariales terminaron por fundamentar una discusión mayor. El sistema jurídico internacional le había perdido la pista al comportamiento, desempeño y conducta de las empresas y, en su defecto, la estructura creada para estar al tanto sobre las movidas empresariales no tuvo el impacto esperado. Los ordenamientos jurídicos propios del sistema romano-germánico como el derecho de sociedades, el modelo mercantil y administrativo así como los del common law del derecho consuetudinario comparado, y de los negocios internacionales quedaron por fuera de las necesidades requeridas para consolidar propuestas solucionadoras a la crisis.

La dimensión de la situación tuvo tanto impacto en el contexto del derecho, y particularmente en el derecho penal, que fue necesario alertar sobre la capacidad de respuesta de este ante la clase de actos que no solamente rayaron bajo el carácter de delitos sino que tomaron el matiz de actos criminales por la manera lesiva y perniciosa con que fueron cometidos, y las salidas que a la postre trataron de mostrar los ejecutores de los mismos para salir avantes del llamado de la justicia, perjudicando más que a nadie a las empresas, hechos que finalmente impulsaron en Estados Unidos y la Unión Europea la presentación una serie de reformas para mitigar los efectos de la crisis a través de la ley Sarbanes-Oxley y el Informe Winter ${ }^{2}$, respectivamente.

El artículo está compuesto por los siguientes temas: En primer lugar, el análisis de la interacción de los sistemas de justicia con respecto a los delitos

\footnotetext{
Leyes que tenían como finalidad evitar fraudes como los comentados. (Ley Sarbanes Oxley Act., 200230 de Julio): La ley sobre la responsabilidad en la contabilidad de las empresas (Corporate Auditing Accountability Act.) Tomado de Agencia EFE, Wall Street Journal, junio de 2002

2 Titulado "Un moderno marco regulatorio para las Sociedades de Europa", conocido como el informe Winter, publicado el 4 de noviembre de 2002. Presenta un estudio detallado sobre los temas suscitados en materia de reforma del derecho de las sociedades. Ver un análisis detallado de estas reformas en Piqueras (2004)
} 
empresariales. El segundo, el contexto del derecho penal económico sobre el delito empresarial, y el tercero, encaminado a evaluar algunos de los casos más importantes relacionados con los temas. Finalmente, más que un llamado a la unificación, se requiere identificar una posición clara frente al delito desde lo penal y lo económico, y un tránsito, que permita mostrar la interacción de ambos desde el derecho penal económico.

\section{PERSPECTIVA DE LOS SISTEMAS DE JUSTICIA INTERNACIONAL FRENTE A LOS DELITOS EMPRESARIALES}

Los sistemas de justicia internacional presentan un importante rezago con respecto a la evaluación de los delitos empresariales. La naturaleza de los actos económicos y de negocios que realizan las empresas en los mercados internacionales aún no están reglamentados en los sistemas jurídicos internacionales en toda su extensión. Tras la incapacidad declarada de manera momentánea para sortear lo sucedido en los últimos años, en cuanto a los mecanismos requeridos para resolver los hechos presentados, se mostró que en contexto, el análisis empresarial no hace parte del interés de los sistemas y tampoco de ninguna rama en particular del derecho.

Señala Cuberos (2009, p. 12):

Durante los últimos años, la actividad empresarial internacional ha experimentado transformaciones innegables. Las transacciones han estado rodeadas cada vez de mayores complejidades, y se han visto afectadas por la necesidad de contar con mecanismos más ágiles para contar para su concepción, implementación y desarrollo. Estas características han hecho que la instrumentación jurídica de los negocios haya cambiado. Lo que se busca, en últimas, es transformar la forma de ver la solución de las controversias a efectos de no quedar anclados a mecanismos que, si bien pueden ser útiles en el marco de las operaciones domésticas, no resultan saludables a la hora de definir el conflicto que involucre flujos de fondos o mercancías entre países.

La legislación internacional aún tiene una perspectiva conductista y funcional de las empresas. En primer lugar, supone que la acción y la constitución de la empresa son plenamente presumibles y evidentes, razones que sólo implican el reconocimiento y control de su actividad. En segundo lugar, desde la funcionalidad, se explican los propósitos que dan origen a las empresas, señalados en la creación y acumulación de riqueza. Ambas perspectivas implican considerar las acciones de las empresas como actos libres sobre los que la sociedad y los sistemas jurídicos deben ser vigilantes o controladores, mas no represivos.

Señala Szczaranski (2008, p. 5):

El asunto de la capacidad penal y de la necesidad de pena respecto de las entidades colectivas no es nuevo, si bien cobra en estos tiempos particular relevancia por el rol actual de las empresas en todas las actividades imaginables, llegando, en muchas áreas, a desplazar casi del todo a las personas naturales aisladas. Así ocurre en el mundo interconectado al que pertenecemos, y ello ha dado lugar a regulaciones especiales y a la institución de fiscalizadores específicos avocados al control de las personas jurídicas y de las empresas que operan en determinados campos, algunos de los cuales, más aun, les están reservados, excluyendo el operar de personas naturales. Sobre todo el operar de grandes organizaciones empresariales crea nuevos riesgos para bienes jurídicos de interés colectivo y nuevos problemas de imputación, siendo bastante compleja la determinación de los sujetos implicados en un hecho ejecutado por dependientes de una sociedad por ejemplo, en virtud de un acuerdo de su directorio.

No ha sido suficiente el avance del derecho de los negocios internacionales para que se preste atención a estos campos, dado que el derecho en general todavía acoge dicha consideración desde un perfil más fundamentalista que doctrinario, basado 
en la idea de que los principios económicos no deben guiar la acción de la justicia. Sin embargo, parte del inconformismo expresado por las mismas empresas no se traslada al terreno de los fallos o sentencias como tal, sino al desconocimiento que muestran los sistemas jurídicos del mundo empresarial, paradigma que le ha restado fuerza al derecho para legislar y regular las acciones de las compañías. Al respecto apunta Ghersi (2009, p. 1):

Hay una confusión en el concepto de ley, además de una ignorancia de lo que significa. Las autoridades creen que las leyes son gratis, que no cuestan, que uno puede utilizar la ley para su interés individual. Pero la ley es costosa, en términos de tiempo e información. Si se requiere mucho tiempo e información para cumplir la ley, el resultado es que la ley se ignora. La ley sólo se cumple cuando los ciudadanos generalmente encargados de cumplirla la encuentran rentable o tienen algún beneficio de cumplirla. Si el costo de cumplir la ley excede a los beneficios, entonces no esperen que nadie cumpla esa ley.

La capacidad de evaluar la condición jurídicoeconómica empresarial permitiría determinar el camino sobre las obligaciones, límites y responsabilidades que igualmente tienen las empresas, por el hecho de ser controladas y dirigidas por personas con capacidad de raciocinio para advertir o diferenciar el valor, la ética o las características de sus actos como proclives a ser sancionados o evaluados por la sociedad como sancionables, castigables o penales. Es muy importante señalar que el criterio que tenga la sociedad sobre las actuaciones empresariales es importante e igualmente necesario para que el tema penal abrace el discurso acaecido en las conductas empresariales.

Argumenta Cesano (2009, p. 349):

La combinación de los diversos problemas reseñados ha conducido a que, desde una perspectiva político-criminal, se hayan elaborado distintas respuestas para abordar la criminalidad sucedida en el ámbito empresarial, propuestas que van desde soluciones intermedias que, negando la posibilidad de responsabilizar penalmente a los entes ideales, postulan, ora su punibilidad a título contravencional (con lo cual se traslada el problema del ámbito del derecho criminal al del derecho penal administrativo), ora la utilización — a su respecto- de medidas de seguridad, hasta el surgimiento de una fuerte corriente de opinión que propugna, directamente, la consagración de un doble sistema de imputación.

No sólo es el llamado a la protección ambiental, la responsabilidad material, el buen manejo patrimonial o de los recursos depositados en confianza por la sociedad a través del mercado de valores o activos. Igualmente, las empresas son sujetos básicamente de naturaleza humana y conforme a su discrecionalidad se toman decisiones que si bien no abarcan a la sociedad como tal, pueden tener en consecuencia repercusiones sobre ella que pueden atentar incluso con las condiciones y la vida misma de las personas. Resalta Cesano (2009, p. 365):

En la actualidad, es indiscutible que la empresa se ve enfrentada a una realidad bipolar: puede ser tanto objeto de agresiones perpetradas en su perjuicio, pero, por otro lado, también puede constituirse en un ámbito muy adecuado para la realización de comportamientos ilícitos, con afectación a intereses diversos a los de la corporación. En este último ámbito — al rechazar la responsabilidad penal de la empresa en sí misma- se hace necesario adoptar instrumentos de imputación "aptos para golpear a los reales sujetos-agentes". Entre estos instrumentos, tanto desde ciertos sectores de la doctrina, como en el ámbito jurisprudencial, se destaca la utilidad de las estructuras omisivas.

El hecho de que sea una empresa o la junta directiva el escenario donde se determine el hecho, y que se presuma que este tuvo el espacio o tiempo suficiente para ser verificado o evaluado antes de que se cometiera no quita méritos para catalogarlo, dada la presunción de laforma en que derivo como delito. Tratar de llamar la atención de la empresa 
sobre dichas actuaciones no es un asunto ético o moral, es causal de conductas que deben ser vigiladas, aunque en principio se asuma que en dichos espacios son otros los intereses y menos las acciones lesivas o contraproducentes que pueden crear o motivar actos delictivos o criminales.

Considera Abanto (2005, p. 3):

El área jurídica extrapenal ha sido muy dinámica y ha tenido un gran desarrollo en las últimas décadas; a medida que se ha ido reconociendo la necesidad de proteger los mecanismos básicos de funcionamiento del sistema, se han ido dando leyes especiales encargadas de regular la actuación de los participantes del mercado en distintos sectores. Así han surgido también sendas áreas jurídicas altamente especializadas y autónomas (que antes eran comprendidas bajo un "Derecho económico) tales como: el Derecho de la libre competencia (o Derecho Antitrust), el Derecho de la leal competencia y de la publicidad, Derecho de la propiedad industrial, Derecho bancario, etc. En estas áreas jurídicas también se suele prever un capítulo destinado a las infracciones y sanciones contra ilícitos que atenten contra el bien jurídico protegido. Desde esta perspectiva, en la actualidad la doctrina administrativa y penal entiende que esta parte del Derecho extrapenal (llamado también de manera global "Derecho administrativo sancionador") formaría parte de un Derecho penal en sentido amplio.

El estudio económico de los juicios puede evitar que el proceso y desenlace terminen por constituir el principal costo del caso. El tema hace alusión a los costos que se generan en los procesos jurídicos llevados a cabo, tras las decisiones jurídicas tomadas en los tribunales, cuando el proceso se dilata o el aparato de justicia desconoce el contexto de los negocios internacionales, los cuales asumen la denominación de costos transaccionales. Los inacabados fallos controversiales de litigios entre empresas y Estados se muestran para el caso como el mejor ejemplo. Argumenta Sintura (2007; p. 170-171):
Desde la consolidación de la integración europea y la consecuente posibilidad de emplear espacios judiciales comunes, se advierte una creciente preocupación por los contenidos y alcances del derecho penal económico, en particular por la regulación normativa penal que se recoge en las legislaciones para combatir la llamada criminalidad de las empresas, que utiliza los modernos sistemas de comunicación y las redes comerciales internacionales, para encubrir o asegurar el producto de su actividad delictiva o financiar nuevas operaciones.

El análisis de los procesos judiciales y de los fallos emitidos en los sistemas jurídicos merece un espacio propio. Dicho escenario puede ser apreciado a partir de la evaluación de los costos de transacción que generan los hechos jurídicos en los temas mencionados. Los costos de transacción están definidos bajo la perspectiva de que en ocasiones la carga o sanción impuesta puede ser superior o inferior al mismo daño o situación que se está juzgando, y es importante para el efecto definir procesos de negociación que permitan no llevar el caso a sanción o castigo de los sistemas jurídicos. Señala Coase (2000, p. 524-525):

Los jueces tienen que decidir sobre la responsabilidad legal, pero esto no debe confundir a los economistas sobre la naturaleza del problema económico. A menudo, el razonamiento empleado en la corte para determinar los derechos legales parece extraño para los economistas, porque muchos de los factores sobre los que se toma la decisión son, para ellos, irrelevantes. Debido a esto, situaciones que desde el punto de vista del economista son idénticas, serán tratadas muy distintamente por las cortes. Pero se debe recordar que la cuestión inmediata enfrentada por las cortes no es lo que se hará, sino quién tiene derecho legal a hacerlo. Siempre es posible modificar mediante transacciones de mercado la delimitación legal inicial de los derechos. Y, por supuesto, si tales transacciones de mercado no tienen costo, siempre tendrá lugar la recomposición de los 
derechos si conduce a un incremento del valor de la producción.

Existen elementos que no permiten entrar de lleno a ejemplificar la acción de la justicia sobre las empresas y empresarios, situación que evidencia que el tema aún no hace parte del contexto jurídico cuando de imponer sanción se trata de manera tajante a no ser que la situación elevada a una categoría superior de crisis o circunstancia negativa así lo obligue como, por ejemplo, las crisis económicas por cuenta de los malos manejos empresariales. Indica Beyer (1992, p. 17-18):

No necesariamente es deseable responsabilizar por daños a las empresas que los provocan, pero también que no es deseable que las empresas nunca sean responsables por dichos daños. No hay aquí, entonces, una defensa indiscriminada de la empresa como muchos de los críticos de Coase han tendido a sostener. Lo que si hay es un deseo de que cada situación particular se evalúe de modo de minimizar (maximizar) los costos (beneficios) para la sociedad.

La posibilidad de definir claramente los campos de discrecionalidad lesiva que pueden atraer dichas conductas es en últimas la base para que el derecho penal contemple estas áreas como igualmente propias de su campo. Más que el afán por orquestar un listado de delitos o la confinación de los mismos a un estado del arte para que haya manera de sancionarlos internacionalmente, es la observación que se hace sobre las conductas empresariales que deben criminalizarse. Por cierto, puede ser este uno de los impedimentos que se tenga a la hora de valorar la conducta delictiva de las empresas. Recalca de nuevo Abanto (2005, p. 7):

Así, en lo que se refiere a la creación de nuevos tipos penales (sobre todo de peligro abstracto) para proteger nuevos bienes jurídicos relacionados con el "funcionamiento" de instituciones económicas, se ha discutido desde hace mucho si ello sería legítimo para un Derecho penal de Estado de Derecho o si implicaría una ruptura con el principio de subsidiaridad y de mínima intervención. El sector dominante de la doctrina penal busca explicar esto a través del replanteamiento de la teoría de bienes jurídicos (existencia de bienes jurídicos colectivos, supraindividuales) y de la lesividad (empleo de técnicas de tipos de peligro abstracto-concreto, de aptitud).

Frente a esto, existe un cierto re-plegamiento del derecho a la hora de considerar estos temas, pues al frente de estas situaciones se responde con otras formas de derechos como el administrativo o civil, pero en ningún momento se rescata en esencia la base penal que pueden tener estas conductas, las cuales deben considerarse como criminales. En los contratos y el desarrollo de nuevos negocios son las áreas en donde más se presentan debilidades jurídicas para evaluar situaciones de carácter empresarial.

Reafirma Henao (2004, p. 528):

Es totalmente coherente con el sistema la introducción de bienes jurídicos difusos, sociales o colectivos, característicos de la expansión del derecho penal, bienes jurídicos que demuestran que la sociedad no es estática y que debido a esta cualidad es necesario que el derecho se desarrolle con ella. Esto nos lleva a concluir que el derecho penal debe adaptar sus instituciones, dinamizándolas frente a las nuevas exigencias de protección y seguridad que requiere la sociedad moderna, pero sin renunciar a las garantías y principios que protegen al ciudadano como núcleo esencial de la sociedad, ya que éste no es un medio para que funcione la sociedad, sino un fin en sí mismo que debe y no puede instrumentalizarse en un Estado social y democrático de derecho.

Para que esta posibilidad sea considerada, es un hecho que la estructura jurídica en temas económicos, de inversiones y de negocios tendrá no sólo que avanzar para que se convierta más que en una carga económica en un activo en las decisiones empresariales. Igualmente la justicia internacional 
debe estar atenta a las alteraciones que de manera excéntrica provoca el mercado, porque detrás de él se terminan por cometer delitos tanto del derecho como de la economía. (Ver cuadro 1).

El posible marco jurídico-económico creado por las empresas internacionales a través de las distintas transformaciones a las que han correspondido como multinacionales o transnacionales, entre otras, deja sin capacidad de respuesta a los sistemas jurídicos ante dificultades legales que pueden presentarse con cargo a la manera como actúan, y por el desconocimiento de los sistemas jurídicos para evaluar algún tipo de delito, hecho que pone en evidencia la crisis del derecho interno como normativa para analizar el comportamiento jurídico-económico empresarial internacional.

\section{EL DELITO EMPRESARIAL FRENTE AL DERECHO PENAL ECONÓMICO}

La estructura conceptual desde la perspectiva penal está claramente definida en cuanto a la capacidad que tiene ésta para evaluar y valorar las acciones delincuenciales que se cometan desde las empresas. No obstante, el aislamiento que el cuerpo doctrinario penal hace con respecto a la posibilidad de permitir desde sus bases la fundamentación para la caracterización de los delitos empresariales y de los negocios no es claro. Propone Cesano (2005, p. 14):

Una respuesta razonable sería esta: si para enfrentar, con un mínimo de efectividad, estas formas de delincuencia transfronteriza resulta necesario conformar estrategias basadas en

Cuadro 1. Fallas del derecho y la economía frente a la evaluación de los delitos empresariales.

\begin{tabular}{|c|c|}
\hline Fallas del Derecho & Fallas de la Economía \\
\hline $\begin{array}{l}\text { 1. No tener presente casos similares en materia de } \\
\text { juicios económicos y de negocios internacionales, a } \\
\text { excepción del common law en comparación con los } \\
\text { demás sistemas jurídicos. }\end{array}$ & $\begin{array}{l}\text { 1. Desincentivar su aplicación en los casos jurídicos, al } \\
\text { centrar el debate en un sentido de eficiencia y no de } \\
\text { justicia, que al fin de cuentas es el objeto central del } \\
\text { derecho. }\end{array}$ \\
\hline $\begin{array}{l}\text { 2. No considerar la agilidad del proceso como parte de } \\
\text { la acción del derecho, en cuanto a la rápida solución } \\
\text { de los casos y más aún en los temas de los negocios } \\
\text { internacionales. Despropósito que igualmente agota } \\
\text { al aparato de justicia. }\end{array}$ & $\begin{array}{l}\text { 2. Aislar su aplicación por contemplar los hechos } \\
\text { jurídicos en un manifiesto económico, y no una } \\
\text { combinación de ambos. }\end{array}$ \\
\hline $\begin{array}{l}\text { 3. Continuar resolviendo casos a partir de prescripcio- } \\
\text { nes jurídicas provistas en los códigos de comercio. }\end{array}$ & $\begin{array}{l}\text { 3. No clarificar su papel como principio del derecho, } \\
\text { más que de imperativo del mismo. }\end{array}$ \\
\hline $\begin{array}{l}\text { 4. La falta de expertos a escala jurídica en temas econó- } \\
\text { micos, de negocios internacionales y de inversiones } \\
\text { entre otras, hecho que dificulta en gran medida la } \\
\text { labor del sistema jurídico en la aplicación de justicia } \\
\text { en estos campos. }\end{array}$ & $\begin{array}{l}\text { 4. No contar con una corriente fuerte que restablezca } \\
\text { el sentido económico del derecho, pues ésta ha } \\
\text { venido fortaleciéndose paradójicamente por los } \\
\text { jueces económicos de los países desarrollados, y } \\
\text { no propiamente por los economistas que pretenden } \\
\text { dar la pelea desde la economía y no desde el terreno } \\
\text { jurídico. }\end{array}$ \\
\hline $\begin{array}{l}\text { 5. No se cuentan con herramientas que permitan } \\
\text { evaluar de manera técnica y profesional las circuns- } \\
\text { tancias como acontecen los casos. }\end{array}$ & $\begin{array}{l}\text { 5. La economía sigue explicando su acción desde } \\
\text { modelos económicos y no desde el sentido de los } \\
\text { sistemas jurídicos, hecho que no permite la discusión } \\
\text { desde la jurisprudencia como normatividad. }\end{array}$ \\
\hline
\end{tabular}

Fuente: elaboración propia. 
la cooperación judicial penal internacional, el respeto del principio de doble tipicidad-como exigencia de la extradición- torna imperativa homogeneizar (desde una perspectiva legislativa) ciertos aspectos del Derecho penal material.

La condición que ostentan las empresas en los mercados internacionales como actividad legalmente constituida no puede servir para aislar o desviar los hechos penales cuando tras de ellas igualmente emergen ilícitos, se presenta así, una cierta dualidad entre lo que se concibe como empresa legal e ilegal, puesto que sobre esta última se cataloga desde la forma criminal como se advierte que realiza su actividad, dejando el tema de dicha denominación a una comprensión igualmente social o de Estado, como por ejemplo, cuando se trata del tema de las drogas, contrabando o evasión de impuestos que igualmente tienen tinte criminal. Al respecto argumenta Cesano (2005, p. 21):

$\left.1^{\circ}\right)$ Desde una perspectiva de análisis teórico, el proceso de internacionalización del Derecho penal económico reconoce diversas manifestaciones; a saber: a) la creación, por parte de instancias supranacionales, de figuras delictivas comunitarias, diseñadas para la protección de bienes jurídicos regionales (V.gr.: competencia, intereses financieros comunitarios) y b) la armonización sectorial de las legislaciones nacionales, con la finalidad de facilitar la cooperación judicial en materia penal, como instrumento para enfrentar la criminalidad organizada trasnacional que afecte intereses económicos locales.

$2^{\circ}$ ) Este proceso no está exento de dificultades. Los problemas que se observan son diversos, de acuerdo a la manifestación que asume la internacionalización (según la sistematización realizada en la conclusión anterior) y a las características jurídicas propias del fenómeno integracionista.

La tipificación penal del delito empresarial ha sido definida en atención de la aquiescencia que al respecto el derecho penal como tal ha definido. En cuanto a la posibilidad de vincularlo como delito penal, esta aseveración parte de señalar el acto, hecho o situación como un episodio que afecta no sólo la moral de la empresa si no además de la sociedad quien debe asumir o reparar el daño que tras de la empresa o del sujeto económico derive el delito consumado. De otro lado, La corriente clásica del derecho penal, indica que no es necesario ningún cambio a la hora de evaluar el delito.

Indica Bombini (2009, p. 2):

Resulta ya un lugar común en los estudios sobre el tema de la "criminalidad económica" acentuar los problemas de imprecisión y controversias que surgen al procurar establecer una conceptualización consensuada científicamente de esta categoría.

Es cada contexto el que determina la naturaleza del delito, por ende, hay posturas que advierten que incluso la posibilidad de internacionalizar los delitos dista de una opción clara por la forma como son considerados o evaluados en cada país. En principio por la naturaleza, en segundo por la conducta, y en tercero por los resultados o daños que eventualmente provocaría la situación catalogada desde el contexto penal. Es casi improbable, según ellos, que exista alguna forma para que sean definidos y contemplados delitos penales de las empresas de manera generalizada. En cuanto a la posibilidad de elevar los delitos empresariales a penales en sentido estricto, la razón parte de las consecuencias que dichos actos registran para la sociedad. Señala Cuadrado (2007, p. 126-127):

Se puede afirmar que la responsabilidad penal de la persona jurídica no sólo ofrece nuevas perspectivas, sino que, además, ha recobrado importancia y actualidad. La realidad social demuestra que existen personas jurídicas de muy variada índole, «con nombre y apellido», que defraudan a sus clientes, a los ciudadanos de una población, venden productos alimenticios caducados o sin la composición que se 
anuncia, blanquean dinero negro u ocasionan problemas de contaminación ambiental y de manera evidente alteran la ordenación del territorio o atentan contra el patrimonio histórico. Lo cierto es que las aguas están revueltas. De un tiempo a esta parte, diría yo, el principio «societas delinquere non potest» duerme mal, está intranquilo, inquieto. Un poco como aquellos que de algún modo se sienten culpables y su conciencia no les deja en paz.

Entre tanto, el distanciamiento del derecho penal en estos temas puede tener sentido, si se analiza el origen y naturaleza de la firma creada y la forma como están definidos el control y dirección de la misma. La presunción de los delitos penales circunscritos a conductas ya abiertamente aprobadas como tal no implica que no se puedan alertar otras formas desde el derecho penal. A ello, ha de abonarse la necesidad de que el derecho se vuelva quantum de la realidad o el hecho que evalúa. Más que dificultades, lo que tiene abierto el derecho penal es la posibilidad de volverse aprehensible y verificable. Explica Terradillos (2006, p. 92):

Un proceso de criminalización que es ejercicio de poder, desigualmente distribuido en los diversos mercados, no puede responder a pautas únicas, ni puede aceptarse como "natural". Con lo que las características definidoras de lo penalmente tutelable no pueden ser universalmente compartidas. Ni puede hablarse de una política criminal uniforme, sino de diferentes alternativas impuestas por la desigualdad originaria.

Puede ser que la imputación sea uno de los obstáculos para desarrollar a cabalidad el derecho penal económico por cuenta de las diversas estructuras sobre las cuales se apoya la conformación empresarial, asimismo como el tipo de sanción o pena que deba asumir más allá de la recuperación de lo perdido o la devolución de los recursos no administrados correctamente. Sustenta Henao (2004, p. 511):
La teoría del delito es una construcción metodológica que interpreta hechos humanos atribuyéndoles a los mismos un sentido concreto, siendo claro que la misma tiene que servirse de valores que le sean útiles para la atribución de sentido al hecho analizado: no se puede olvidar que el hecho es un fenómeno histórico, ya pasado, y su dimensión de sentido tiene la potencialidad de ir mutando con el paso del tiempo: la propia historia en tanto que "ciencia interpretativa" enseña como hechos pasados son vistos de modo muy diverso con el paso del tiempo. Si el hecho por definición no sufre cambios, la dimensión comunicativa -su carácter delictivo- sí los puede experimentar. Esto significa que la virtualidad delictiva del hecho es dinámica y dependiente de las necesidades y valores que una comunidad pretenda privilegiar en un espacio de tiempo establecido. Precisamente por eso es difícil rechazar que la teoría del delito haya de tener una fuerte dimensión teleológica, lo que obliga a racionalizar la intervención del derecho penal con base en un sistema que se preocupe por detectar cuáles son los valores que imprimen sentido a cada categoría y que finalidades persiguen los mismos.

La estructura del derecho penal ha sido la que ha actuado como guía para analizar la conducta lesiva, dañina o perjudicial de los individuos para con la sociedad. Sobre ella, la individualidad del delito ha sido un elemento latente a la hora de evaluar y valorar la acción desde lo penal. Considerada a su paso, como la base de los sistemas jurídicos, pues de ella son derivadas de cierta manera las diferentes formas de derecho creadas a medida que se enmarcan en uno u otro espacio, en donde el derecho requiere ser redefinido de acuerdo con las condiciones del espacio o región que se considere como en el caso del derecho penal económico.

Contextualiza Szczaranski (2008, p.1):

Las grandes empresas -organizadas operacionalmente como personas jurídicas- constituyen, en el mundo actual de los negocios, una categoría trascendente que el devenir social y 
económico ha venido perfilando como eventuales nuevos sujetos peligrosos en el ámbito del delito. Esto crea, en particular, problemas de imputación ya que es bastante compleja la determinación de los sujetos implicados. El estudio de las personas jurídicas como nuevos sujeto crimonógenos, indica, a la vez, que cada vez es más relevante la afectación criminal de bienes jurídicos colectivos, además de los individuales relacionados con la seguridad física y patrimonial de las personas naturales. Recientes casos de interés internacional han conmovido la opinión pública en conexión con actividades empresariales de impacto social general: accidentes aéreos y terrestres; balances falsos que arrastran consigo a los anónimos accionistas; desastres químicos contaminantes que lesionan el medio ambiente y quiebras fraudulentas, por mencionar algunos.

Existe la posibilidad de que aún se insista en mantener la discusión del tema fuera del alcance penal, pero no se puede presumir que las conductas delincuenciales obedezcan a actos por fuera de los sistemas sociales o económicos. El derecho penal ha sido concebido como la figura más sobresaliente del análisis jurídico positivista, pues desde él son consideradas todas las conductas que atentan contra el equilibrio de las instituciones frente a las malas actuaciones de los individuos. Al respecto Anota Nieto (2008, p. 12):

Pero a mi juicio, el futuro del derecho penal de la empresa en lo tocante a la responsabilidad del superior va más allá que la de aportar nuevos argumentos a una discusión, como la del deber de garantía, en la que ya se han gastado demasiados esfuerzos con muy poca claridad. De la estructura de la autorregulación que examinábamos en un apartado anterior (III), se deduce la importancia que tienen los deberes de documentación de aquellas actividades empresariales en la que exista riesgo de aparición de comportamientos delictivos. Igualmente se ha constatado una preocupación porque circule fluidamente, y sobre todo de abajo- arriba, la información empresarial relativa a la compliance, y no solo aquella que tiene que ver con el cumplimiento de los fines económicos. Esta situación no solo facilita la imputación subjetiva de los superiores, sino que también me parece relevante a la hora de discutir la legitimidad de la sanción por imprudencia dentro del derecho penal económico, con el fin de sancionar penalmente a los administradores que de forma grave se han apartado de su deber de conocer. Incluso y más allá de este debate, la importancia de los nuevos deberes que surgen de la autorregulación debe llevarnos a discutir si en el derecho penal europeo debe incluirse como tercera forma de imputación subjetiva dolosa, el desconocimiento deliberado (willful blindness), forma de dolo que es tradicional en el derecho norteamericano. En materias como la corrupción o el blanqueo de capitales, las infracciones más intolerables de la obligación de conocer lo que ocurre bajo sus pies por parte de los administradores, no debería beneficiarse de las penas más benévolas del delito imprudente.

La comisión de delitos que se han detectado cuando han sido analizados casos de naturaleza empresarial, y que por la magnitud de sus actuaciones conduce a señalarlas desde el matiz criminal, obliga a avanzar por encima de la discusión aislada y poco provechosa del análisis que la doctrina penal hace en estos terrenos. Llevar el tema a un terreno prolijo en otras áreas permite darle fuerza y capacidad de justicia al proceso, y evaluación del delito como tal.

\section{DELITOS EMPRESARIALES Y ACCIÓN DE LA JUSTICIA INTERNACIONAL}

El espacio de debate en la materia ya ha sido dado; referentes en todo el mundo hablan de la necesidad de vincular algunas prácticas empresariales dentro de la estructura del derecho y régimen penal. Más allá de la misma apertura hacia una derivación de este último, lo que se ha intentado es mostrar que frente al comportamiento de las organizaciones debe haber más claridad, por cuanto sus conductas, 
al igual que las cometidas por sujetos particulares, pueden ser lesivas o infinitamente perjudiciales para cualquier individuo o incluso otras empresas.

Argumenta Terradillos (2006, p. 95):

Si la globalización no impulsa la expansión penal en el ámbito económico, sino que está objetivamente condenada a restringirla, procede ahora re-examinar la influencia del resto de presuntas causas determinantes de aquélla. Aunque puede adelantarse que su incidencia es desigual $\mathrm{y}$, al menos en el ámbito de la delincuencia socioeconómica, mucho más irrelevante de lo que se pretende.

Existe la posibilidad de que aún se insista en mantener la discusión del tema fuera del alcance penal, pero no se puede presumir que las conductas delincuenciales obedezcan a actos por fuera de los sistemas sociales o económicos, dado que responden a comportamientos catalogados como no sociales cuando su procedencia tiene como epicentro actos ilícitos realizados por grupos igualmente sindicados de perversos ante la sociedad como la mafia, grupos al margen de la ley, delincuencia organizada, y hasta la misma delincuencia común. Frente a esta encrucijada se evalúan dos perspectivas por parte de Feijoo (2009, p. 7-8):

Responsabilidad preferente de los que actúan en último lugar (el modelo de imputación bottom up). Existe cierto acuerdo en la doctrina de que la solución fácil de que la responsabilidad penal pille preferentemente a los últimos que ejecuten el hecho o tengan el riesgo empresarial entre las manos (los últimos eslabones de la cadena empresarial) debe ser evitada como modelo general en la medida en la que no se trata de una solución adecuada a la estructura de las organizaciones empresariales.

El contra-modelo top down a las teorías tradicionales de la autoría. Se puede observar en la actualidad una tendencia dominante, tanto en el ámbito de la teoría como de la práctica forense relativa a la delincuencia empresarial, que consiste en entender que, salvo supuestos excepcionales, los dirigentes de la empresa ostentan la responsabilidad preferente por los hechos delictivos realizados en beneficio de las empresas. En este sentido es cada vez más normal en casos de outputs lesivos de una empresa, que, en todo caso, acabe respondiendo penalmente algún directivo o miembro cualificado de dicha empresa, al menos por no haber sido cuidadoso a la hora de organizarla internamente para controlar su peligrosidad.

Frente a estas circunstancias se requiere, además, que la justicia entienda que detrás de las empresas existen más elementos y redes de lo que se piensa, y que de no anticipar circunstancias como éstas, no habrá poder sancionatorio que valga, porque al parecer los escándalos más que por los hechos, son alborotos que provienen de la forma como la justicia responde ante ellos aduciendo no conocer el tipo de prácticas o argumendo que el sistema jurídico no estaba preparado para dirimir acciones delictivas, que ya se consideraban superadas, o peor aún, que no tenían por qué tener conocimiento o acceso a ellas por ser de exclusivo carácter de las empresas, quedando abierta la inquietud sobre quién legisla o vigila las empresas o qué sistemas jurídicos en realidad tienen clara la importancia de separar la justicia en tantas áreas como sea posible, como por ejemplo aconteció recientemente en Colombia por cuenta de la Fiscalía señalado en el diario El Colombiano (2007, p. 5a):

La torpeza, la falta de idoneidad y la imprudencia han caracterizado a la Fiscalía General de la Nación en el manejo del caso BancolombiaGilinski. La Fiscalía General de la Nación desconcierta y preocupa con su errónea actuación en el caso Bancolombia-Gilinski. Y no es para menos. El pasado jueves 4 de enero, el fiscal Octavo Delegado, Diógenes Villa Delgado, dictó resolución de acusación contra el presidente de Bancolombia, Jorge Londoño Saldarriaga, y el vicepresidente de servicios de la misma entidad, Federico Ochoa Barrero, ordenando su detención domiciliaria. Pero al miércoles siguiente, 11 de enero, revocó de oficio la 
medida y les concedió la libertad inmediata e incondicional. Fundamenta esta decisión en el hecho de haber aplicado la anterior legislación y no el nuevo Código de Procedimiento Penal, Ley 906 de 2004, que no contempla la detención domiciliaria para los presuntos delitos de que son acusados los funcionarios.

La sanción no sólo puede relacionarse con un daño estrictamente corporal, tras las vacilaciones de las compañías o equivocaciones igualmente se presentan daños e impactos para todos aquellos relacionados con los movimientos de las empresas o de sus líderes. Al respecto, existe la necesidad de contar con un derecho y sistema de justicia más acorde con la realidad económica e internacional de de las empresas internacionales, que en realidad no gozan de observación, protección y claridad jurídica internacional (Ver cuadro 2).

Cuadro 2. Algunos casos jurídicos-económicos y costos transaccionales.

\begin{tabular}{|c|c|c|}
\hline Caso & Análisis jurídico - económico & Costos transaccionales \\
\hline $\begin{array}{l}\text { 1. Licorera de Caldas ganó } \\
\text { caso en Inglaterra. Portafo- } \\
\text { lio }(2007 a, \text { p. } 3) \text {. }\end{array}$ & $\begin{array}{l}\text { La oficina de marcas del Reino Unido } \\
\text { decidió a favor de la industria licorera } \\
\text { de Caldas (ILC) la demanda que inter- } \\
\text { puso contra Esperanza Maldonado } \\
\text { por apropiación indebida de la marca } \\
\text { Ron Viejo de Caldas. El fallo señala en } \\
\text { su parte resolutiva que la tradicional } \\
\text { marca es de uso exclusivo de la indus- } \\
\text { tria licorera de Caldas, única empresa } \\
\text { autorizada para comercializar directa } \\
\text { o indirectamente sus productos en esa } \\
\text { región del continente europeo. }\end{array}$ & $\begin{array}{l}\text { El Tema de marcas sigue siendo una de } \\
\text { las inquietudes más grandes en cuanto } \\
\text { a casos jurídicos. De un lado, pese a las } \\
\text { exigencias de registro de las mismas, sigue } \\
\text { siendo creciente la copia, la suplantación o } \\
\text { el mismo registro tal cual de la marca. Ésta } \\
\text { situación señala que aún falta por profun- } \\
\text { dizar en los temas de registro, marca, sellos } \\
\text { y demás, en cuanto a lo que concierne a la } \\
\text { parte legal, pero en cuanto a las empresas } \\
\text { que entran en dichos casos se requiere } \\
\text { conocer a cabalidad el protocolo jurídico y } \\
\text { características generales y especificas del } \\
\text { producto. Es decir, que el campo jurídico } \\
\text { debe tener mayor conocimiento en temas de } \\
\text { productos, puesto que es uno de los princi- } \\
\text { pios o elementos centrales para contener la } \\
\text { suplantación de marcas o el sub-registro de } \\
\text { las mismas en diferentes latitudes. }\end{array}$ \\
\hline $\begin{array}{l}\text { 2. Accionistas de Granaho- } \\
\text { rrar ganaron pleito a la Na- } \\
\text { ción por } \$ 224.000 \text { millones, } \\
\text { Portafolio }(2007 b, \text { p. } 22) \text {. }\end{array}$ & $\begin{array}{l}\text { Nueve años después de que el gobierno } \\
\text { de Andrés Pastrana intervino para } \\
\text { liquidar a Granahorrar, el Consejo de } \\
\text { Estado encontró que la entidad finan- } \\
\text { ciera no estaba insolvente como en su } \\
\text { momento lo argumento la Superbanca- } \\
\text { ria (octubre de 1998). Por esta razón, la } \\
\text { Nación, a través de la Superintendencia } \\
\text { Financiera y el Fogafin, deberán pagarle } \\
\text { a seis sociedades accionistas de Gra- } \\
\text { nahorrar } 224.000 \text { millones de pesos. }\end{array}$ & $\begin{array}{l}\text { El tiempo que tiene valor económico, aún no } \\
\text { hace parte de las cuentas de los costos de } \\
\text { justicia de muchos sistemas jurídicos, pues- } \\
\text { to que todavía reza el discurso apologético, } \\
\text { que la justicia tarda pero llega. La justicia } \\
\text { debe buscar mecanismos que permitan } \\
\text { ser ágil en los procesos y las decisiones, y } \\
\text { sí sobre ello deben proponerse aspectos } \\
\text { como los de la lógica jurídica o la jurimetria, } \\
\text { pues bienvenida sea la sistematización } \\
\text { o iuscibernetica a los sistemas jurídicos } \\
\text { internacionales, porque la real justicia no } \\
\text { es la que tarda, sino la que es constante e } \\
\text { inmediata. }\end{array}$ \\
\hline
\end{tabular}

(continúa) 
Cuadro 2. Algunos casos jurídicos-económicos y costos transaccionales.

(Continuación)

\begin{tabular}{|c|c|c|}
\hline Caso & Análisis jurídico - económico & Costos transaccionales \\
\hline $\begin{array}{l}\text { 3. A tribunal de arbitraje, } \\
\text { lio por la planta de Tibitoc, } \\
\text { Portafolio (2007c, p. 11). }\end{array}$ & $\begin{array}{l}\text { El Centro de Arbitraje y Conciliación } \\
\text { de la Cámara de Comercio de Bogotá } \\
\text { se declaró competente para resolver } \\
\text { una demanda presentada por la Em- } \\
\text { presa de Acueducto y Alcantarillado } \\
\text { de Bogotá (Eaab) contra la concesión } \\
\text { de Tibitoc. Sin embargo, según anunció } \\
\text { esta firma, de común acuerdo se deci- } \\
\text { dió suspender los términos entre el } 13 \\
\text { de diciembre y el } 20 \text { de enero próximos, } \\
\text { para que se entre a resolver la disputa } \\
\text { en el } 2008 \text {. El tribunal estudiará la } \\
\text { cancelación anticipada por parte de la } \\
\text { Eaab, el contrato de concesión de la } \\
\text { planta de Tibitoc. } \\
\text { La Eaab argumento, para proceder con } \\
\text { esta cancelación, que las estimaciones } \\
\text { de demanda de agua potable en la } \\
\text { ciudad cambiaron con respecto a las } \\
\text { proyecciones previstas cuando se } \\
\text { suscribió el mismo contrato. }\end{array}$ & $\begin{array}{l}\text { De manera recurrente el Derecho Interna- } \\
\text { cional Privado empieza a tomar demasiada } \\
\text { fuerza. De ahí, que muchas empresas se } \\
\text { dirijan a este tipo de justicia. Lo preocupan- } \\
\text { te del asunto es que en muchos casos son } \\
\text { las diferentes y ambiguas providencias las } \\
\text { que preocupan. Es decir, que al parecer hay } \\
\text { una justicia desde la óptica pública y otra } \\
\text { desde la privada, que obliga a indicar que } \\
\text { no son claros los parámetros y variables de } \\
\text { análisis cuando se miden los casos desde } \\
\text { los sistemas civiles ordinarios o arbitrales } \\
\text { y conciliatorios. Siendo necesario analizar } \\
\text { los elementos que los hacen distintos y } \\
\text { que sus providencias sean tan erráticas y } \\
\text { contradictorias. }\end{array}$ \\
\hline
\end{tabular}

Fuente: Construcción a partir de publicaciones de Portafolio (2007).

En cuanto a la manera como se presenta cada uno de los casos, el análisis jurídico-económico empresarial debe estar dirigido a considerar tres aspectos cruciales: el primero, en virtud del concepto que un país puede definir para así desde el punto de vista jurídico, económico y social, y lo que para su interior en correspondencia con las formas de empresas en el mundo, puede constituir o asumir la definición de empresa internacional. El segundo, en la forma de concebir los negocios y los mercados de las empresas internacionales desde el vínculo legal y la caracterización para la realidad del país en donde decide instalarse. Y el tercero, la necesidad de considerar los actos de naturaleza empresarial como principios y fuentes de derecho económico internacional para tener elementos que apoyen la acción de la justicia y los sistemas jurídicos internacionales sobre las empresas internacionales.

\section{CONCLUSIONES}

El papel del derecho es fundamental no sólo como elemento doctrinario sino como perfil aplicado de la oferta profesional de quienes se forman de manera integral para el mundo de las empresas. Las escuelas de derecho y de economía particularmente de los países latinoamericanos han tardado en posibilitar en sus estructuras académicas análisis empresariales que realmente contextualicen las problemáticas a las que están enfrentadas las empresas, más allá de las tradicionalmente abordadas como las de producción, mercadeo y ventas que comúnmente han recaído en el cuerpo de las áreas empresariales.

La cantidad de casos relacionados con delitos empresariales ha sobrepasado la capacidad de respuesta jurídico-económica internacional, por 
ende, es imperante estimular el análisis y estudio del derecho penal económico en las compañías y organizaciones, por cuanto el grado de diseminación al que han sido abocadas en otras formas de derecho no ha correspondido con las exigencias reales que ellas plantean para contar con un derecho moderno que resulte pertinente a la hora de analizar las dificultades de tipo empresarial consideradas.

Frente a la forma como ha sido abordado el escenario de delitos cometidos en las empresas, queda para el análisis una serie de cuestionamientos vinculados con el quehacer de la fundamentación y acción, tanto del campo jurídico como del económico en las empresas. El distanciamiento característico de estas áreas de estudio ha dificultado la posibilidad de acrecentar el conocimiento jurídico-económico que requieren las empresas para su propia sobrevivencia.

Permitir a las empresas la posibilidad de internalizar los actos de naturaleza jurídica-económica como tema gerencial es un camino que debe recorrerse, instancia que permitiría superar el estado de cuenta y de responsabilidad sobre el cual es asumido el ejercicio del derecho en las empresas. Es importante convertir esta área en una unidad de apoyo para las compañías desde un perfil con carácter academicista de cara a la retroalimentación que igualmente se requiere de estos campos por parte de los procesos de investigación emanados en las universidades, posibilitando la creación de un cuerpo colegiado y un ámbito corporativo que igualmente genere propuestas alrededor del tema.

Para el análisis jurídico-económico es importante profundizar acerca del grado de maleabilidad que presentan las empresas internacionales. Amparar el estado de cuestión en la definición interna de lo que puede constituirse al respecto no es factor para llevar a cabo dicha actividad. Las pautas en materia jurídico-económica están siendo definidas por los delitos que se cometen y hasta ahora dicho margen es el que ha caracterizado el escenario de los sistemas jurídicos.
La tarea finalmente es incentivar el análisis del derecho penal económico, bajo la idea de suscitar el desarrollo institucional del derecho como una herramienta de trabajo de orden gerencial de doble vía, tanto para los actos jurídicos realizados por las compañías de manera ordinaria por cuenta de sus actividades, como para el abordaje que del mismo debe darse por parte de los sistemas jurídicos.

\section{BIBLIOGRAFÍA}

Abanto Vásquez, Manuel A. (2005). El derecho penal en una economía de mercado, influencia de la integración económica y la globalización. Artículo de ponencia basado en la conferencia dictada en Facultad de Derecho la Universidad Andrés Bello de Viña del Mar (Chile), en el marco del Seminario "La persecución de ciertos delitos a la luz de la nueva justicia procesal penal", llevada a cabo del 16 al 27 de agosto de 2005, p. 1-55.

Beyer, Harald (1992). Ronald H. Coase y su contribución a la teoría de la economía y el derecho. Estudios Públicos 45, Universidad de Chile, pp. 1-22.

Bombini, Gabriel (2009). La criminalidad económica como problema criminológico y político criminal. Buenos Aires: Centro de Investigación Interdisciplinaria en Derecho Penal Económico (CIIDPE). p. 1-20.

Cesano, José Daniel (2005). Criminalidad económica e internacionalización del derecho penal: experiencias en la unión europea y en el Mercosur. Buenos Aires: Centro de Investigación Interdisciplinaria en Derecho Penal Económico (CIIDPE), p. 1-27.

Cesano, José Daniel (2009). La imputación penal en el ámbito de la empresa y las estructuras omisivas: bases para su análisis. Exposición del autor en el marco de la Especialización de Derecho Penal del Mercosur, dictado por la Secretaría de Posgrado de la Facultad de Derecho de la Universidad Nacional de Buenos Aires, p. 341-370.

Coase Ronald (2000). El problema del costo social. En: Roemer, Andrés (compilador). Derecho y economía: una revisión de la literatura (p. 512-556), $1^{\text {a }}$ ed., México. Centro de Estudios de Gobernabilidad y Políticas 
Públicas, A. C., Instituto Tecnológico Autónomo de México y Fondo de Cultura Económica de México.

Cuadrado Ruiz, M. Ángeles (2007). La responsabilidad penal de las personas jurídicas. Un paso hacia adelante... ¿un paso hacia atrás? Revista Jurídica de Castilla y León. N. ${ }^{\circ}$ 12. España, pp. 121-152

Cuberos De las casas, Felipe (2009). Una nueva visión de los conflictos empresariales, s.v. Administración, Diario PORTAFOLIO. 2 de febrero de 2009, lunes, Año 15, numero 3207. Casa editorial El TIEMPO, Bogotá, Colombia, p. 12.

El Colombiano (2007). La chambonada de la Fiscalía. Editorial. 14 de enero, s.v., Opinión, Medellín, p. 5a.

Feijoo Sánchez, Bernardo (2009).imputación de hechos delictivos en estructuras empresariales complejas. Buenos Aires: Centro de investigación interdisciplinaria en derecho penal económico (CIIDPE), 30p.

Ghersi, Enrique (2009). Las consecuencias jurídicas del mercantilismo. [En línea] El Cato.org, Lima, Perú, 9p. Disponible en: http://www.elcato.org/pdf files/ ens-2009-10-30.pdf. [Consultado enero de 2010].

Henao Cardona, Luis Felipe (2004). ¿El Derecho penal puede y debe transformar radicalmente sus contenidos de protección? En: Revista Estudios Socio-Jurídicos, Vol. 6, No 2, Universidad del Rosario, Bogotá, p. $501-533$

Nieto Martín, Adán (2008). Responsabilidad social, gobierno corporativo y autorregulación: sus influencias en el derecho penal de la empresa. [En línea] Revista Política. Criminal. No 5, Universidad Castilla de la Mancha, España, 18p. Disponible en: http:www.politicacriminal. cl/n_ 05/a_3 _ 5.pdf. [Consulta: 14 Octubre de 2010].
Piqueras Bautista, Rafael (2004). El nuevo marco del derecho de sociedades. Director Corporativo de Asuntos Jurídicos de Repsol YPF Web de la Compañía (www.repsolypf.com). Ponencia realizada en el marco de los Elementos esenciales del Derecho Societario en el Centro de Estudios Jurídicos del Ministerio de Justicia, España, p. 535-561.

Portafolio (2007a). Licorera de Caldas ganó caso en Inglaterra. Colombia, 2 de noviembre, p. 3.

Portafolio (2007b). Accionistas de Granahorrar ganaron pleito a la Nación por \$224.000 millones. Colombia, 20 de noviembre, p. 22.

Portafolio (2007c). A tribunal de arbitraje, lío por la planta de Tibitoc. Colombia, 20 de noviembre, p.11.

Sintura Varela, Francisco José (2007). Estudios de derecho penal económico. $1^{a}$ ed., Editorial Universidad del Rosario, Bogotá, p. 170-186.

Szczaranski Cerda, Clara Leonora (2008). Las personas jurídicas como nuevos sujetos criminógenos. En: Derecho Penal. Revista de derecho 17 dos.indd Sec2:31; Santiago de Chile, p. 1 -62

Terradillos Basoco, Juan María (2006). Globalización, administrativización y expansión del derecho penal económico. Nuevo Foro Penal, No 70, Universidad EAFIT, Medellín, p. 86-115.

Winter, Jaap (2002). Informe Winter: informe del grupo de alto nivel sobre derecho de sociedades. [En línea] Unión Europea, Bruselas, 165p. Disponible en: http://www. boe.es/boe/dias/2003-07-18/pdfs/A28046-28052.pdf [Consulta: 14 octubre de 2010]. 